\section{Rehabilitation Treatment Strategies in Ankylosing Spondylitis}

To the Editor:

We read with great interest the recent article by Masiero, et al regarding the efficacy of exercise combined with an educational-behavioral program in patients with stabilized ankylosing spondylitis (AS) ${ }^{1}$.

We agree that physical therapy has remained a mainstay for the treatment of AS in order to reduce pain, preserve spinal flexibility, prevent postural deformities, and improve muscle strength. Although tumor necrosis factor- $\alpha$ (TNF- $\alpha$ ) antagonism has dramatically changed the therapeutic opportunities for patients with AS by providing symptom relief and thus improving quality of life, it is very expensive for the national health system. In this perspective, rehabilitation combined with an educationalbehavioral program could represent an effective choice for those AS patients in remission after the discontinuation of anti-TNF- $\alpha$ agents. We agree with Masiero, et al that the "old" rehabilitation therapy is regaining credit in this "new" biologic era.

Our work ${ }^{2}$ indicated that combination treatment with etanercept and an intensive spa rehabilitation program was more effective than pharmacological therapy alone in a large group of patients with AS. In particular, our data demonstrated that the quality of life, as measured by EQ-5D visual analog scale, showed a statistically significant improvement in favor of the combination therapy group. The main limitation of our study was that it was not randomized.

Rehabilitation treatment should be conducted in all AS patients because of its effectiveness and its safety, even more if carried out in a supervised spa setting ${ }^{3}$. But to date we have no data permitting us to understand whether this therapeutic strategy can yield a consistent benefit over the very long natural history of AS, and further studies with longer followup are required. It would be of great interest to evaluate the efficacy of the combi- nation therapy in patients with early axial spondyloarthropathies, in whom a greater improvement would be expected. It is also worth recalling that, in Italy and in other countries, rehabilitation represents an additional fee for patients. Therefore, a joint effort to establish the effectiveness of rehabilitation in AS and to ensure patients' access to rehabilitation programs is needed. Indeed, there is the possibility that these combined strategies may result in substantial longterm savings by the national health system.

MATTEO COLINA, MD, Section of Internal Medicine A, Department of Internal Medicine, Ospedale Maggiore, Bologna, Italy; GIOVANNI CIANCIO, MD; MARCELLO GOVONI, MD, Rheumatology Section, Department of Clinical and Experimental Medicine, University of Ferrara, Corso della Giovecca 203, Ferrara 44100, Italy. Address correspondence to Dr. Colina; E-mail: matteo.colina@gmail.com

\section{REFERENCES}

1. Masiero S, Bonaldo L, Pigatto M, Lo Nigro A, Ramonda R, Punzi L. Rehabilitation treatment in patients with ankylosing spondylitis stabilized with tumor necrosis factor inhibitor therapy. A randomized controlled trial. J Rheumatol 2011;38:1335-42.

2. Colina M, Ciancio G, Garavini R, Conti M, Trotta F, Govoni M. Combination treatment with etanercept and an intensive spa rehabilitation program in active ankylosing spondylitis. Int J Immunopathol Pharmacol 2009;22:1125-9.

3. Dagfinrud H, Kvien TK, Hagen KB. The Cochrane Review of physiotherapy interventions for ankylosing spondylitis. J Rheumatol 2005;32:1899-906.

J Rheumatol 2011;38:10; doi:10.3899/jrheum.110691 